\title{
Incomplete Antenatal Steroid Therapy Can Enhance Outcomes in Preterm Infants with Emergency Conditions
}

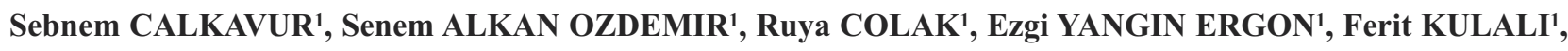 \\ Tulin GOKMEN YILDIRIM1
}

Izmir, Turkey

\section{ABSTRACT}

OBJECTIVE: We aimed to investigate the role of incomplete of antenatal steroid therapy by comparing with no and complete steroid exposure on mortality and morbidity in preterm infants.

STUDY DESIGN: This is a prospective, an observational study which includes preterm infants of 32 weeks of gestation and/or $\leq 1500$ grams who were referred to Izmir Dr. Behcet Uz Children's Hospital NICU during the one year period. Infants were divided into three groups according to the administration of antenatal steroid as those who received incomplete-dose antenatal steroid, complete dose steroid therapy and those with no steroid exposure. Intubation at the delivery room, surfactant requirement, the inotropic requirement in the first 72 hours and morbidities associated with prematurity were determined as the primary results. Mortality and bronchopulmonary dysplasia at discharge and stage $\geq 2$ retinopathy were analyzed as secondary outcomes.

RESULTS: We found that 54 infants were born with an incomplete dose, 55 infants with complete dose and 38 infants with no steroid therapy. Surfactant requirement, inotropic requirement, and hemodynamically significant patent ductus arteriosus were lower in the steroid exposure group leading to a statistical difference $(p<0.05)$. Also, it was found that mortality and Bronchopulmonary dysplasia was lower in the incomplete and complete dose steroid groups, leading to a statistical difference $(p<0.05)$.

CONCLUSION: We speculate that even incomplete dose steroid may reduce mortality by reducing respiratory distress syndrome.

Keywords: Antenatal corticosteroids, Prematurity, Respiratory distress syndrome, Surfactant

Gynecol Obstet Reprod Med 2020;26(1):64-69

\section{Introduction}

Infants born at or before 25 weeks' gestation have the highest mortality rate (approximately 50 percent) $(1,2)$. Advances in neonatal intensive care unit (NICU) and antenatal steroid (AS) therapy to prevent and treat neonatal respira-

${ }^{I}$ Neonatology, Division of Neonatology, Dr. Behcet Uz Child Disease and Pediatric Surgery Training and Research Hospital, Izmir

Address of Correspondence:

Senem Alkan Ozdemir

Behcet Uz Children's Hospital, Department

of Neonatology, 35210 Alsancak, Izmir,

Turkey

drsenemalkan@yahoo.com

Submitted for Publication:

Revised for Publication:

03.07 .2019

21.07.2019

13.09.2019

SC: 0000-0002-3820-2690,

ORCID IDs of the authors:

SAO: 0000-0003-0474-7120,

EYE: 0000-0003-0836-7379,

TGY: 0000-0001-5951-2631

FK: 0000-0003-0310-1184,

\begin{tabular}{|c|c|}
\hline Quick Response Code: & Access this article online \\
\cline { 2 - 2 } & Website: www.gorm.com.tr \\
& e- mail: info@gorm.com.tr \\
\cline { 2 - 2 } & DOI:10.21613/GORM.2019.994 \\
\hline
\end{tabular}

How to cite this article: Calkavur S. Alkan Ozdemir S. Colak R. Yangin Ergon E. Kulali F. Gokmen Yildirim T. Incomplete Antenatal Steroid Therapy Can Enhance Outcomes in Preterm Infants with Emergency Conditions. Gynecol Obstet Reprod Med 2020;26(1):64-69

tory morbidities have resulted in decreased mortality rates of preterm infants $(2,3)$.

Antenatal administration of corticosteroids (AS) accelerates the development of pneumocytes, leading to structural changes that improve both lung mechanics and gas exchange (4). Liggins and Howie for the first time in 1972 showed that glucocorticoid administration in pregnancies improved the lung maturation and reduced the incidence of respiratory distress syndrome (RDS) $(5,6)$. Many studies have reported the benefits of steroid administration in the antenatal period, it is also reported at the last Cochrane review that the AS reduces the incidence of RDS by $34 \%$, and additionally reduces intraventricular hemorrhage (IVH), necrotizing enterocolitis (NEC), respiratory support, and mortality (7). These benefits may be the effect of the respiratory recovery and maturational changes in numerous tissues due to corticosteroid stimulation of developmentally regulated genes (8). For this reason, AS is the standard treatment for all pregnancies at risk of preterm birth worldwide.

However, this may not always be possible in cases of emergency in terms of, threatening the life of the baby or mother and the baby may be born with the incomplete treatment of AS or no AS. There are only a few studies investigat- 
ing the relationship between mortality and morbidity when AS is not performed completely.

In this study; we aimed to investigate the role of incomplete of antenatal steroid therapy by comparing with no and complete steroid exposure on mortality and morbidity in preterm infants.

\section{Material and Method}

The NICU at Behcet Uz Children's Hospital is a referral center for treating rare and complex medical conditions in neonates. This prospective and observational study was conducted at the Neonatology Clinic of Behcet Uz Children's Hospital (level IV NICU, in Izmir, Turkey), between January 2017 and January 2018. Ethical approval from the Behçet Uz Child Hospital Ethics Committee (2016/81) was obtained and conformed to the tenets of the Declaration of Helsinki. The aims of the study were explained, with an interpreter whenever necessary and written informed consent was obtained.

Preterm infants with a gestational age of $\leq 32$ weeks and/or birth weight $\leq 1500 \mathrm{~g}$ were included in the trial. The exclusion criteria for the study were major congenital anomalies and congenital infections.

A single dose of antenatal steroid treatment until 24 hours before birth was considered "incomplete treatment of antenatal steroid therapy". The infants were divided into two groups, those who had incomplete treatment of AS and those who did not receive any AS.

Respiratory distress syndrome was diagnosed according to the clinical parameters determined by the neonatologist (9).

Respiratory rate $>60 / \mathrm{min}$,

Respiratory distress in evidence of dyspnea, cyanosis, intercostal, and subcostal retraction,

Appearing within 4-6 hours after delivery,

Oxygen requirement (any percentage) to prevent cyanosis

Chest X-ray changes (ground glass appearance and air bronchograms).

IVH is diagnosed by cranial ultrasound on day three of life and graded according to the Papile classification (10). NEC is diagnosed according to the Bell stage (11).

Clinically significant patent ductus arteriosus (PDA) was diagnosed when there was color Doppler echocardiographic evidence of left to right ductal shunt associated with at least 2 of the following clinical signs: heart murmur, persistent tachycardia (HR >160/min), hyperactive precordial pulsation, bounding pulses, differential pulse pressure $(>30 \mathrm{mmHg})$ or hyperactive precordial pulsation, hypotension, and presence of radiographic evidence of cardiomegaly or pulmonary edema (12).

Retinopathy of prematurity (ROP) is classified according to The International Classification for Retinopathy of Prematurity (ICROP) (13).

Infants were examined periodically after discharge in the Preterm Birth Clinic at Behcet Uz Children's Hospital and formal neurodevelopmental testing was conducted at an adjusted age of 12 to 24 months. Data obtained from Preterm Birth Clinic records included the Bayley Scales of Infant Development II, which included the Mental Developmental Index (MDI) and the Psychomotor Developmental Index (PDI), performed by Developmental of Behavioral Pediatrician.

\section{Study intervention}

The infants were stabilized on NCPAP (Neopuff; Fisher and Paykel, Auckland, New Zealand) in the delivery room and during transport to the NICU. All of the infants were started on prophylactic caffeine at NICU admission. Noninvasive ventilation was started within $30 \mathrm{~min}$ of birth immediately. Noninvasive ventilation was delivered by a neonatal ventilator (SLE 5000, Germany) via short, binasal prongs (Fisher and Paykel Healthcare Ltd., UK). $\mathrm{FiO}_{2}$ was titrated at 0.21-0.50 to maintain an oxygen saturation level of $90 \%-95 \%$, as measured via pulse oximeter. The infants treated with surfactant according to Turkish Neonatal Society RDS guideline which is based to European RDS guideline (14). Under non-invasive ventilation, the surfactant (poractant alfa $200 \mathrm{mg} / \mathrm{kg}$ ) was administered as rescue therapy if the infant required $\geq 0.40 \mathrm{FiO}_{2}$ to maintain the target saturation level of $90 \%-95 \%$. Blood gas measurements were performed by the clinical team as needed (14).

The primary outcomes were intubation within 72 hours, surfactant requirement, usage of inotropic agent within 120 hours, presence of hemodynamically significant PDA, ROP (stage $\geq 2$ defined as per international classification), NEC (stage $\geq 2$ based on Bell's criteria) and severe IVH (grade III and IV IVH) in both groups. Duration of invasive/noninvasive ventilation, oxygen dependency, mortality at discharge and bronchopulmonary dysplasia (oxygen dependency at 36 weeks postmenstrual age, BPD) were our secondary outcomes. We also recorded maternal and neonatal demographics and SNAPPE II

\section{Statistical analysis}

Statistical analyses were performed using the SPSS software package for Windows (SPSS, Inc., Chicago, IL). Quantitative variables were expressed as mean \pm standard deviation (SD) and median (minimum/maximum) and categorical variance was expressed as $\mathrm{n}(\%)$ in the charts. Variables were examined at $95 \%$ confidence level and the $p$-value was considered to be less than 0.05 . A descriptive analysis of the 
demographic and clinical characteristics of the infants was conducted. Student's t-test for parametric data or MannWhitney U test for non-parametric data were used for comparison of variables between the groups. One-way ANOVA was used for multiple comparisons. Chi-square test was used to compare ratios between the two groups.

\section{Results}

During the study period, 276 preterm infants whose gestational age of $\leq 32$ weeks and/or birth weight $\leq 1500$ g were admitted to NICU of which 147 infants were considered eligible for the study. One hundred and forty-seven infants have studied: 54 infants were incomplete dose AS group, 55 infants with complete dose and 38 infants with no steroid exposure. The study population consisted of infants who were $29.3 \pm 2.3$ (mean \pm SD) weeks' gestation (range 23-32 weeks) and 1283.2 $\pm 206($ mean $\pm \mathrm{SD})$ grams (range 630-1.500 g).

No significant differences were observed between the three groups in terms of demographic characteristics and respiratory status at NICU admission. The demographic characteristics of the groups are given in table I.

According to primary outcomes; surfactant and inotropic requirements, and hemodynamically significant PDA
(hsPDA) were statistically different between groups $(p<$ $0.05)$. The incidence of severe IVH was statistically lower in incomplete and complete steroid therapy groups $(p=0.01)$. No differences were observed in stage $\geq 2$ NEC and stage $\geq 2$ ROP between the groups. No pneumothorax was observed in any of the patients during the study period. The comparison of primary outcomes was given in table II.

According to the secondary results, the duration of non-invasive ventilation was similar between the groups and the duration of the total duration of oxygen support was lower in the group with the incomplete treatment of antenatal steroids ( $p=$ $0.20, p=0.018$, respectively). Mortality and bronchopulmonary dysplasia (BPD) rates were lower in the incomplete AS group, leading to statistical difference ( $p=0.01, p=0.03$ ). The comparison of secondary outcomes was given in table III. Duration of mechanical ventilation and the total duration of oxygen support were shown in figure 1 .

As shown in table III, there was no significant difference between either MDI or PDI scores between groups.

In the subgroup analysis of incomplete dose AS and complete course AS therapy, there was no difference in primary and secondary outcomes. It was shown in table IV.

Table I: Baseline characteristics of the infants

\begin{tabular}{lllll}
\hline Parameters & $\begin{array}{l}\text { Incomplete dose AS } \\
(\mathbf{n}=\mathbf{5 4})\end{array}$ & $\begin{array}{l}\text { No steroid therapy } \\
(\mathbf{n}=\mathbf{3 8})\end{array}$ & $\begin{array}{l}\text { Full course AS } \\
(\mathbf{n}=\mathbf{5 5})\end{array}$ & $\begin{array}{l}\boldsymbol{p} \\
\text { value }\end{array}$ \\
\hline Gestational week (week) $^{*}$ & $29.5 \pm 2.2$ & $28.9 \pm 2.3$ & $29.2 \pm 2.7$ & 0.54 \\
Male gender (\%) & $30(55)$ & $17(44)$ & $31(56)$ & 0.16 \\
C\&S (\%) & $39(72)$ & $28(73)$ & $40(72)$ & 0.56 \\
Birth weight (g) & $1297.2 \pm 290$ & $1263.4 \pm 284$ & $1190.5 \pm 395$ & 0.23 \\
Preeclampsia (\%) & $15(27)$ & $10(26)$ & $21(38)$ & 0.20 \\
Gestational DM (\%) & $2(3)$ & $2(5)$ & $3(5)$ & 0.92 \\
\hline
\end{tabular}

*as presented mean $\pm S D$

Table II: Major neonatal morbidities and need for therapies

\begin{tabular}{|c|c|c|c|c|}
\hline Parameters & $\begin{array}{l}\text { Incomplete dose AS } \\
(n=54)\end{array}$ & $\begin{array}{l}\text { No steroid therapy } \\
(n=38)\end{array}$ & $\begin{array}{l}\text { Full course AS } \\
(n=55)\end{array}$ & $\begin{array}{l}p \\
\text { value }\end{array}$ \\
\hline Intubation in $72 \mathrm{~h} \mathrm{( \% )}$ & $17(31)$ & $22(57)$ & $20(36)$ & 0.06 \\
\hline Administration of surfactant (\%) & $23(42)$ & $26(68)$ & $22(40)$ & 0.01 \\
\hline hsPDA (\%) & $12(22)$ & $16(42)$ & $9(16)$ & 0.007 \\
\hline Inotropic treatment $(\%)$ & $6(11)$ & $13(34)$ & $8(14)$ & 0.02 \\
\hline Stage $\geq 3$ IVH $(\%)$ & $3(5)$ & $4(10)$ & $0(0)$ & 0.01 \\
\hline Stage $\geq 2$ NEC (\%) & $1(1.8)$ & $2(5)$ & $3(5)$ & 0.44 \\
\hline Invasive mechanical ventilation (day) ${ }^{*}$ & $3(0-41)$ & $0(0-46)$ & $0(0-25)$ & 0.16 \\
\hline Total duration of oxygen support (day) ${ }^{*}$ & $7(1-116)$ & $14(2-105)$ & $12(0-86)$ & 0.14 \\
\hline Duration of hospital stay (day) ${ }^{* *}$ & $39.6 \pm 18.7$ & $50.3 \pm 23.7$ & $30.0 \pm 21.2$ & 0.22 \\
\hline
\end{tabular}



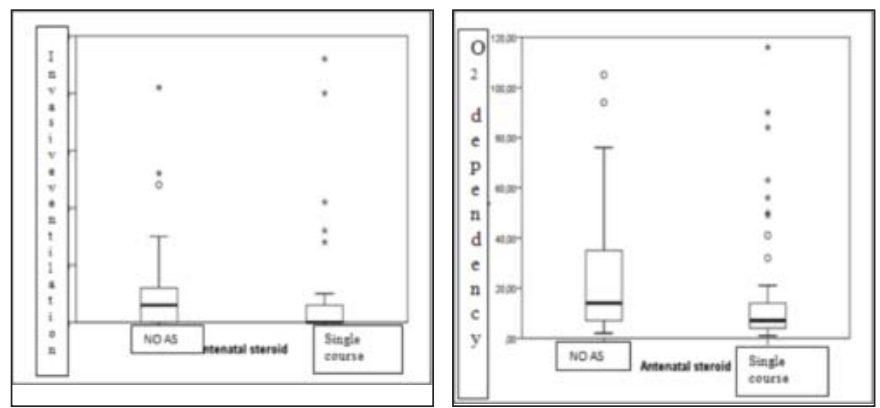

Figure 1: Duration of $\mathrm{O}_{2}$ dependency and invasive ventilation

\section{Discussion}

In this trial, we compared the effect of incomplete AS therapy with no and complete steroid exposure on short and long term outcomes in preterm infants. We found that AS exposure either incomplete or complete AS therapy reduced the surfactant administration, incidence of severe IVH and inotropic treatment. Also, incomplete AS therapy and complete AS therapy were compared in subgroup analysis and we found no difference in short and long term outcomes.

Antenatal steroid administration is the most effective method for reducing neonatal mortality and morbidity $(5,6)$. AS administration can be applied in two ways. First, $12 \mathrm{mg}$ betamethasone (two doses in total) is administered at 24-hour intervals or $6 \mathrm{mg}$ dexamethasone (4 doses in total) is administered at 12-hour intervals during the treatment $(6,7)$. The most effective period of the treatment is considered as the time between 24th hour and 7th day after the onset of the steroid treatment. Cochrane meta-analysis (7) published in 2017 and included 30 studies and 8158 infants, it was shown that the antenatal steroid treatment prominently reduced the neonatal mortality and morbidity. This important effect of AS is rather important particularly in infants under 30 weeks (7).

There is limited data that the incomplete treatment of antenatal betamethasone and dexamethasone administrations reduces morbidity. The effects of AS on infants were investigated by Lau et al. and it was shown that the effect of AS was significantly reduced after the $7^{\text {th }}$ day $(15)$. However, babies born without no administration of AS treatment were not included in the analysis. In an animal model with low-dose betamethasone on preterm lambs, the effects of single-dose intramuscular betamethasone therapy were shown to be similar to those of double-dose in terms of significant improvement in dynamic and static lung compliance, gas exchange and ventilation effectiveness (16). It was shown that a single-dose of betamethasone-acetate has an effect on the fetal lung growth with that of the double-dose and the lung function improves 8

Table III: Neonatal secondary outcomes in the study

\begin{tabular}{lllll}
\hline Parameters & $\begin{array}{l}\text { Incomplete dose treatment } \\
(\mathbf{n}=\mathbf{5 4 )}\end{array}$ & $\begin{array}{l}\text { No steroid therapy } \\
(\mathbf{n}=\mathbf{3 8})\end{array}$ & $\begin{array}{l}\text { Full course AS } \\
(\mathbf{n}=\mathbf{5 5})\end{array}$ & $\begin{array}{l}\boldsymbol{p} \\
\text { value }\end{array}$ \\
\hline Mortality at discharge (\%) & $0(0)$ & $4(10)$ & $0(0)$ & 0.004 \\
BPD at discharge (\%) & $7(12)$ & $12(31)$ & $8(14.5)$ & 0.05 \\
Stage $\geq$ 2 ROP (\%) & $7(12)$ & $8(21)$ & $15(27)$ & 0.36 \\
\hline Parameters & Incomplete dose treatment & No steroid therapy & Full course AS & $\boldsymbol{p}$ \\
& $(\mathbf{n = 3 0 )}$ & $\mathbf{( n = 3 0 )}$ & $\mathbf{( n = 5 3 )}$ & value \\
\hline MDI Score* & $98.1 \pm 24.1$ & $96.7 \pm 14.0$ & $97.7 \pm 11.4$ & 0.97 \\
PDI Score* & $92.5 \pm 23.5$ & $93.2 \pm 17.0$ & $93.7 \pm 18.5$ & 0.99 \\
\hline
\end{tabular}

*BPD: Bronchopulmonary dysplasia; ROP: Retinopathy of prematurity; MDI: Mental Developmental Index; PDI: Psychomotor Developmental Index

Table IV: Subgroup analysis of incomplete dose AS and complete course AS therapy

\begin{tabular}{llll}
\hline Parameters & $\begin{array}{l}\text { Incomplete dose AS } \\
(\mathbf{n}=\mathbf{5 4 )}\end{array}$ & $\begin{array}{l}\text { Full course AS } \\
(\mathbf{n}=\mathbf{5 5})\end{array}$ & $\begin{array}{l}\boldsymbol{p} \\
\text { value }\end{array}$ \\
\hline Administration of surfactant (\%) & $23(42)$ & $22(40)$ & 0.46 \\
BPD at discharge (\%) & $7(12)$ & $8(14.5)$ & 1.0 \\
Stage $\geq 2$ ROP (\%) & $7(12)$ & $15(27)$ & 0.09 \\
Stage $\geq 2$ NEC (\%) & $1(1.8)$ & $20(36)$ & 0.20 \\
Intubation in 72 h (\%) & $17(31)$ & $8(14)$ & 0.46 \\
Inotropic treatment (\%) & $6(11)$ & $9(16)$ & 0.77 \\
hsPDA (\%) & $12(22)$ & $0(0)$ & $\mathrm{NS}$ \\
Mortality (\%) & $0(0)$ & $0(0)$ & 0.11 \\
Stage $\geq 3$ IVH (\%) & $3(5)$ & & \\
\hline BPD: Br)
\end{tabular}

BPD: Bronchopulmonary dysplasia; ROP: Retinopathy of prematurity; NEC: Necrotizing enterocolitis; hsPDA: Hemodynamically significant patent ductus arteriosus; IVH: Intraventricular hemorrhage 
15 hours after the steroid administration (16). Therefore, the efficacy of steroid therapy administered just before birth suggests that the effect will increase even if just a drop with a single-dose administration as it extends over time. Salhab et al. (17) indicated that each AS dose is effective in reducing the neonatal morbidity. In the present study, preterm infants with similar SNAPPE II. and conditions were compared with infants who with no and complete course of AS. In infants who were administered an incomplete treatment, PDA rates, inotropic treatment, and administration of surfactant were lower. Additionally, BPD and mortality rates at discharge were lower in infants who were administered at least one dose of steroid. This speculates that even short-term exposure to intrauterine betamethasone may improve pulmonary functions.

In the present study, the surfactant requirement was found to be lower in infants receiving an incomplete treatment of AS and the rate of mortality decreased depending on the improvement of pulmonary results. This difference may be related to the increasing nCPAP usage; the steroid treatment will be more beneficial in term of pulmonary outcomes.

Immature myocardium in preterm infants has reduced contractile element, altered calcium release and decreased betaadrenoreceptor and reduced sympathetic innervation (18). The AS administration is particularly effective in the development of oxygen sensitivity in the ductus arteriosus tissue (19). However, preterm infants who are not exposed to AS are also considered to be at risk in terms of PDA because of inadequate data (20). In the present study, the inotropic treatment and the frequency of PDA requiring treatment were significantly low in incomplete AS therapy group. It is thought that this could be arising from the improvement of oxygen sensitivity in the ductus arteriosus tissue with the incomplete AS therapy.

Observational studies indicate that the significant influence on the pulmonary outcomes is closely related to the gestational week (21). In the NICHD Neonatal Research Network outcomes, a total of 10,541 infants who were born between the 22nd-25th gestational weeks were evaluated, and it was seen that the rate of neonatal mortality was lower with the use of AS, however, among the surviving infants, infants who received a complete cure of AS had higher BPD rates than those who did not (22). In another multicenter study, a total of 2549 babies $<29$ weeks of age were included in the study and, the $\mathrm{BPD}$ rate was found to be higher in infants who received a complete AS therapy than those who did not receive it (23). On the other hand, in another study where 11.607 infants were examined, no significant correlation was found between the use of AS and the BPD ratios (24). These differences between the studies can be attributed to the fact that the studies have different BPD definitions and more infants survived with the administration of AS in infants at earlier gestational weeks. Wong et al., (23) showed that there was no change in the mortality ratios with the incomplete treatment AS treatment, however, the study had a very low number of cases. The present study includes only infants who were born under the $32^{\text {nd }}$ gestational week with very low birth weight and showed that the BPD and the rate of mortality were lower with steroid exposure.

The most important aspect of this study is the fact that it reveals the difference between the preterm infants who received an incomplete treatment AS and those who did not. According to our results, incomplete AS therapy was superior to no steroid exposure. This study clearly shows that even an incomplete-dose could reduce the rate of morbidity and mortality. We found that infants admitted to NICU with similar conditions and SNAPP-E scores by the same staff in a singlecenter had lower rates of neonatal morbidity and mortality with the administration of incomplete treatment of AS.

There are several limitations of our study. First, it was a single-center study and a small study group. Second, we do not have long term outcomes.

In conclusion, the complete course of AS therapy should be administered in suspicion of preterm birth. The complete course of AS is the gold standard but if it is not possible, incomplete AS treatment may be life-saving especially in developing countries, due to antenatal follow-up is not regular.

Acknowledgment: None

Funding: None

Conflict of interest: Authors declare no conflict of interest Author contribution: SC: Designed study, data collection and preparation of the manuscript. SAO: Designed study, data collection and preparation of the manuscript. RC: Data collection and preparation of the manuscript. EYE: Data collection and preparation of the manuscript. FK: Data collection and preparation of the manuscript. TGY: Preparation of the manuscript.

\section{References}

1. Shahzad F, Umar N. Impact of antenatal corticosteroids on frequency and mortality due to respiratory distress syndrome in preterm neonates. J Ayub Med Coll Abbottabad. 2016;28(4):698-701.

2. Blencowe H, Cousens S, Oestergaard MZ, Chou D, Moller AB, Narwal R, et al. National, regional, and worldwide estimates of preterm birth rates in the year 2010 with time trends since 1990 for selected countries: a systematic analysis and implications. Lancet. 2012;379(9832):216272.

3. Horbar JD, Carpenter JH, Badger GJ, Kenny MJ, Soll RF, Morrow KA, et al. Mortality and neonatal morbidity among infants 501 to 1500 grams from 2000 to 2009 . Pediatrics. 2012;129(6):1019-26.

4. Bonanno C, Wapner RJ. Antenatal corticosteroid treatment: what's happened since Drs Liggins and Howie? Am J Obstet Gynecol. 2009;200(4):448-57.

5. Liggins GC, Howie RN. A controlled trial of antepartum 
glucocorticoid treatment for prevention of the respiratory distress syndrome in premature infants. Pediatrics. 1972;50(4):515-25.

6. Miyazaki K, Furuhashi M, Ishikawa K, Tamakoshi K, Hayashi K, Kai A, et al. Long-term outcomes of antenatal corticosteroids treatment in very preterm infants after chorioamnionitis. Arch Gynecol Obstet. 2015;292(6): 1239-46.

7. Roberts D, Brown J, Medley N, Dalziel SR Antenatal corticosteroids for accelerating fetal lung maturation for women at risk of preterm birth. Cochrane Database Syst Rev. 2017;3:CD004454.

8. Ervin MG, Padbury JF, Polk DH, Ikegami M, Berry LM, Jobe AH. Antenatal glucocorticoids alter premature newborn lamb neuroendocrine and endocrine responses to hypoxia. Am J Physiol Regul Integr Comp Physiol. 2000; 279(3):R830-8.

9. Greenough A. Respiratory distress syndrome. In: Rennie JM, editor. Textbook of neonatology. Londra: Churchill Livingstone; 2012. p. 468-85.

10. Papile LA, Burstein J, Burstein R, Koffler H. Incidence and evolution of subependymal and intraventricular hemorrhage: a study of infants with birth weights less than 1,500 gm. J Pediatr. 1978;92(4):529-34.

11. Gupta A, Paria A. Etiology and medical management of NEC. Early Hum Dev. 2016;97:17-23.

12. $\mathrm{Su} \mathrm{BH}$, Watanabe $\mathrm{T}$, Shimizu $\mathrm{M}$, Yanagisawa $\mathrm{M}$. Echocardiographic assessment of patent ductus arteriosus shunt flow pattern in premature infants. Arch Dis Child Fetal Neonatal Ed. 1997;77(1):36-40.

13. International Committee for the Classification of Retinopathy of Prematurity. The International Classification of Retinopathy of Prematurity revisited. Arch Ophthalmol. 2005;123(7):991-9.

14. Ozkan H, Erdeve O, Kutman HGK. Turkish Neonatal Society guideline on the management of respiratory distress syndrome and surfactant treatment. Turk Pediatr Ars. 2018;53(Suppl 1):S45-S54.

15. Lau HCQ, Tung JSZ, Wong TTC, Tan PL, Tagore S. Timing of antenatal steroids exposure and its effects on neonates. Arch Gynecol Obstet. 2017;296(6):1091-6.

16. Schmidt AF, Kemp MW, Rittenschober-Böhm J, Kannan PS, Usuda H, Saito M, et al. Low-dose betamethasone-acetate for fetal lung maturation in preterm sheep. Am J Obstet Gynecol. 2018;218(1):132.e1-132.e9.

17. Salhab WA, Hynan LS, Perlman JM. Partial or complete antenatal steroids treatment and neonatal outcome in extremely low birth weight infants $<$ or $=1000 \mathrm{~g}$ : is there a dose-dependent effect? J Perinatol. 2003;23(8):668-72.

18. Alkan Ozdemir S, Arun Ozer E, Bakiler AR, Ilhan O, Sutcuoglu S, Tatli MM. Assessment of hemodynamic changes in preterm infants with respiratory distress syndrome. Anatol J Cardiol. 2017;18(6):440.

19. Clyman RI, Ballard PL, Sniderman S, Ballard RA, Roth $\mathrm{R}$, Heymann MA, et al. Prenatal administration of betamethasone for prevention of patient ductus arteriosus. J Pediatr. 1981;98(1):123-6.

20. Sweet DG, Carnielli V, Greisen G, Hallman M, Ozek E, Plavka R, et al. European Consensus Guidelines on the Management of Respiratory Distress Syndrome-2016 Update. Neonatology. 2017;111(2):107-25.

21. Travers CP, Carlo WA, McDonald SA, Das A, Bell EF, Ambalavanan N, et al. Mortality and pulmonary outcomes of extremely preterm infants exposed to antenatal corticosteroids. Am J Obstet Gynecol. 2018;218(1):130.e1130.e13.

22. Carlo WA, McDonald SA, Fanaroff AA, Vohr BR, Stoll BJ, Ehrenkranz RA, et al. Association of antenatal corticosteroids with mortality and neurodevelopmental outcomes among infants born at 22 to 25 weeks' gestation. JAMA. 2011;306(21):2348-58.

23. Wong D, Abdel-Latif M, Kent A; NICUS Network. Antenatal steroid exposure and outcomes of very premature infants: a regional cohort study. Arch Dis Child Fetal Neonatal Ed. 2014;99(1):12-20.

24. Mori R, Kusuda S, Fujimura M; Neonatal Research Network Japan. Antenatal corticosteroids promote survival of extremely preterm infants born at 22 to 23 weeks of gestation. J Pediatr. 2011;159(1):110-114.e1. 